\title{
Spatial Visualization as Mediating between Mathematics Learning Strategy and Mathematics Achievement among 8th Grade Students
}

\author{
Belal Rabab'h ${ }^{1} \&$ Arsaythamby Veloo ${ }^{1}$ \\ ${ }^{1}$ School of Education and Modern Languages, University Utara Malaysia, Malaysia \\ Correspondence: Belal Rabab'h, School of Education and Modern Language, University Utara Malaysia, Sintok, \\ Kedah, Malaysia. E-mail: Belal.Rababh@yahoo.com
}

Received: November 18, 2014 Accepted: January 5, 2015 Online Published: April 27, 2015

doi:10.5539/ies.v8n5p1

URL: http://dx.doi.org/10.5539/ies.v8n5p1

\begin{abstract}
Jordanian $8^{\text {th }}$ grade students revealed low achievement in mathematics through four periods $(1999,2003,2007$ \& 2011) of Trends in International Mathematics and Science Study (TIMSS). This study aimed to determine whether spatial visualization mediates the affect of Mathematics Learning Strategies (MLS) factors namely mathematics attitude, mathematics motivation, mathematics self-regulation, mathematics self-efficacy, and mathematics anxiety on mathematics achievement. The study consists of 360 students from public middle schools in Alkoura district, selected through stratified random sampling. It employed 65 items to assess MLS, which consists, attitude (18 items), motivation ( 7 items), self-regulation (25 items), self-efficacy (5 items) and math anxiety (10 items). The mathematics test comprises of 30 items, which has eight items for numbers, 14 items for algebra and eight items for geometry while spatial visualization test consists of 32 items base on 2D and $3 \mathrm{D}$ views. The findings showed that spatial visualization fully mediated the relationship between motivation, math anxiety and mathematics achievement and it partially mediated the relationship between attitude and mathematics achievement. However, the results showed no mediating effect between self-regulation, self-efficacy and mathematics achievement. Considering these results, it is recommended that teachers should focus on mathematics attitude, mathematics motivation and math anxiety in classes to make achievement in mathematics easier. Moreover, these factors help students deeply understand mathematics through interest in spatial visualization as it mediates between relevant factors and mathematics achievement.
\end{abstract}

Keywords: spatial visualization; mathematics learning strategy, mathematics achievement, grade eight students

\section{Introduction}

The educational system is primarily viewed as a significant factor forming the basis of an individual's development and progress, and in turn, forms the core of countries' development. As such, more and more focus is being emphasized on the educational systems promotion on a global scale. In the context of Jordan, the government has made considerable efforts in developing its educational system. Such system has experienced tremendous development and increasing progress that date back to the 1920s (Al-Jaraideh, 2009). Owing to the significance of mathematics in the knowledge economy, Jordan's Ministry of Education (MoE) has concentrated on improving students' knowledge, skills and achievement in mathematics (Sabah \& Hammouri, 2010).

The importance of mathematics has been hailed by many studies in literature. According to Drew (1996), mathematics is the most important factor that relates to an individual's success. He proceeded to describe mathematics as a subject that is required for entry into many professions and it is important for existing as well as emerging occupations in a global economy that is based on information and technology. Saffer (1999) also stated that mathematics is not just useful in the day to day skills such as managing money but also in the most popular occupations and countless of jobs that call for some mathematical skill or another. This is the reason why mathematics is hailed at a higher rate compared to other subjects, and it has been called as the queen of all sciences and servant to all disciplines (Ajayi, Lawani, \& Adeyanju, 2013).

A student's proficiency in mathematics in schools is reflective of the related other variables or a combination of variables comprising academic and non-academic variables including individual characteristics, mathematics attitude , motivation, self-concept, self-confidence, self-regulation, equipment and instructional materials for effectively teaching the subject (Ma \& Xu, 2004; Tella, 2007). 
Studies dedicated to the educational field imply that student attitudes toward a subject influence academic success (Popham, 2005; Royster, Harris, \& Schoeps, 1999). Additionally, attitude is among the factors that are gaining more focus from scholars as well as educators. More importantly, studies have highlighted the relationship between attitudes towards mathematics and achievement in the subject (Ma \& Kishor, 1997) as a reciprocal influence where attitudes impact achievement and vice versa. In addition, Hammoury (2004), in her study involving eighth grade Jordanian school students, revealed that attitude directly impacts mathematics achievement. Also, in Eleftherios and Theodosios's (2007) study, attitude is revealed to impact mathematics achievement and mathematics abilities including spatial visualization to memorize formula and procedures.

A second factor that can influence and determine the student's success in school is mathematics motivation. Learner's motivation is viewed as a crucial aspect of effective learning. Even psychologists are convinced that motivation is a necessary element for learning and that satisfactory school learning may not take place without enough learning motivation (Tella, 2007). Additionally, Hammoury (2004) claimed that motivation significantly and positively impacts mathematics achievement among eighth grade students while Cassidy (2002) revealed that motivation is important in problem solving skills.

Another factor that influences learning is mathematics self-regulation as evidenced by Zimmerman and Martinez-Pons's (1990) study which demonstrated its relevance for school students and academic achievement. Self- regulated learning is described as the knowledge and skills acquisition through cognitive and meta-cognitive process and actual behavior (Zimmerman, 2000). Researchers claimed that self- regulation is crucial to the learning process (Jarvela \& Jarvenoja, 2011; Zimmerman, 2008) as it assists students in creating better learning habits, strengthening study skills (Wolters, 2011), applying learning strategies to improve academic outcomes and monitoring their achievement (Harries, Friedlander, Sadler, Frizzelle, \& Graham, 2005) and evaluating their academic progress (De Bruin, Thiede, \& Camp, 2001).

It is also notable that in the past three decades, educational research has stressed on self-efficacy (Joo, Bong, \& Choi, 2000). Bandura (1997) described self-efficacy as the belief in one's capabilities to organize and execute the courses of action needed to be achieved. Therefore, it can be stated that beliefs of self-efficacy can influence student's behavior through its impact upon the decisions of the tasks to engage in, the level of effort expended, and the time duration of persevering in difficult situations. A study has also revealed that self-efficacy is a major predictor of general academic achievement and in mathematics achievement in particular (Zimmerman, 2000).

In studies of meta-analysis, Hembree (1990) and Ma (1999) revealed that mathematics anxiety is inversely related to mathematics achievement. Ikegulu (2000) stated that math anxiety may hinder the developmental achievement of mathematics learners. Moreover, Gourgey (1984) claimed that math anxiety is a factor that leads students to stop trying when they encounter mathematics problems. Math anxiety may lead to higher withdrawal and/or failure rates among students who take developmental mathematics courses.

\subsection{Problem Statement}

The importance of acquiring mathematics knowledge in the world is quite evident owing to its usefulness in everyday life and in several disciplines. The students' low achievement in mathematics in all education levels is the most crucial issue that researchers and educators are concerned about (Abo-lebdeh, 2008). Studies concerning the topic have revealed low level of mathematics achievement of school students, particularly $8^{\text {th }}$ graders (Chouinard et al., 2007; Ikegulu, 2000). This called for several studies to examine the low mathematics achievement of eight graders in schools in general and in Jordanian schools students in particular (Abo-lebdeh, 2008; Hammouri, 2004).

Despite the studies that investigated the different factors of mathematics achievement conducted by prior researchers (Capraro, Young, Lewis, Yetkiner, \& Woods, 2009; Hammoury, 2004), they are still insufficient, and paid minimal attention to schools (Abo-lebdeh, 2008). As such, researchers over the past two decades have examined the low level of mathematics achievement school-going students. According to Mullis, Martin, Foy, and Arora (2012), Jordanian $8^{\text {th }}$ grade students revealed low achievement in mathematics through four periods (1999, 2003, 2007, 2011) of Trends in International Mathematics and Science Study (TIMSS).

Studies claimed that Mathematics Learning Strategy factors are all significant in improving students' mathematical achievement (Areepattamannil, 2014; Ifamuyiwa \& Ajilogba, 2012; Sartawi, Alsawaie, Dodeen, Tii, \& Alghazo, 2012). However, regardless of their comprehensive findings, there is still the need to investigate the factors on a global scale and in the context of Jordan as there is still a gap in literature (Hammoury, 2004; Roviro \& Sancho-Vinuesa, 2012).

Moreover, although spatial visualization has been considered to be significantly related to mathematics 
achievement, findings are inconclusive. Some researchers revealed a positive link between spatial visualization and mathematics achievement (Meyer et al., 2010; Rohde, 2007) and others revealed minimal to no correlation between the two (Lee et al., 2004; Pandisco, 1994).

\section{Literature Review}

Social-Cognitive Theory was presented by Bandura (1986) who came up with the theory and established variables in the learning psychology field, which illustrated several learning techniques. Social cognitive theory is assigned to a model of growing interactive agency. It suggests that a person is not autonomous factor or mechanical conveyers of animating environmental influences. Rather, they develop causal contribution to their own motivation and action encapsulated in a system of triadic reciprocal causation. This provides base for Bandura (1986) conception of reciprocal determinism, which is the fundamental concept on which this model of triadic reciprocal causation is based on. The social cognitive theory put forward by him in 1989 discusses that a person can be a good judge of his own experience and thought processes by self-reflecting, and such self-reflection leads to the evaluation and modification of his environments and social systems. Therefore, social cognitive theory has been used on several fields of psychosocial function such as attitude, anxiety, self-concept, self-regulation and motivation (Landry, 2003). These evaluations contain understanding of self-efficacy.

\subsection{Relationship between Mathematics Achievement and Spatial Visualization}

Spatial visualization is described as a basic skill of understanding and developing primary mathematical skills and a gateway to superior problem solving (Augustynaik, Murphy, \& Phillips 2005). Despite the consensus of several researchers upon the importance of spatial visualization in mathematics learning as they improve the intuitive view and comprehension of various areas of math (Usiskin, 1987), other studies claimed that the relation between the two factors are still not clear (Idris, 1998). Ghbari, Abu-Shendi, and Abu-Sheirah (2008) conducted a study to examine the spatial ability development among Jordanian students. The study sample comprised 221 students randomly selected from various sections, who took a mental rotation test that gauged their spatial ability. The findings showed no differences in performance on the test of spatial ability due to study years. They also showed no significant differences in spatial ability test performance due to social status or academic performance.

Also, Abu-Mustafa (2010) focused on the relationship between spatial ability and the achievement of sixth graders in mathematics in an attempt to determine the impact of the gender variable, and to determine the students' diversity (in terms of high and low spatial abilities). The study sample comprised of students in 6 classes of sixth grade (228 students), distributed to three female classes and three male ones. The study employed the spatial orientation test-Card Rotation-by Whitley Test. The results showed positive correlation between mathematics achievement and students' spatial ability. The results also showed that male students have higher spatial abilities compared to their female counterparts in the application of one way analysis of variance between the scores of both genders. In addition, the results showed that high achievers possess high spatial abilities compared to their average and low achieving counterparts.

The spatial visualization abilities of enrolled engineering students were examined by Seabra and Santos (2008) in order to assess the relationship between spatial abilities, gender and age. The sample consisted of 605 students in mental rotation test and 587 students in visualization test. They revealed significant differences between the genders in terms of their scores in spatial visualization abilities, where male students outperformed female students. Sipus and Cizmesija (2012) investigated the differences in gender in light of spatial ability in Croatia with the help of the Mental Cutting Test. The study sample consisted of 130 students and the findings showed that male students outperformed female students.

Similarly, Meyer, Salimpoor, Wu, Geary, and Menon (2010) examined the differential contribution of particular working memory component to mathematical achievement of 98 students enrolled in San Francisco Bay Area. The study sample was required to take IQ assessments through Wechsler Abbreviated Scale of Intelligence (Wechsler, 1999). The results showed that spatial visualization component was a predictor of mathematical reasoning and numerical operations skills. Meanwhile, Idris (1998) studied the key role of cognitive variables including spatial visualization, field dependence/independence, and Van hiele levels of geometric in mathematics learning among $1376^{\text {th }}-8^{\text {th }}$ graders enrolled in the Franklin County School in the United State of America (U.S.A). The findings revealed spatial visualization to be related to mathematics achievement. Rohde (2007) revealed that from the three spatial factors namely visualization, perceptual speed, and closure speed, the first factor explained major variance in academic achievement and math achievement with independence from general intelligence. The author contended that visualization does not only influence math achievement but also scholastic achievement on the whole. 
More evidence revealing the relationship between spatial visualization and mathematics was provided by Lee, S. $\mathrm{Ng}$, E. Ng, and Lim (2004). Their study is an investigation of the central executive functions comprising of phonological loop and spatial visualization sketchpad, and mathematical achievement among 10 year old students in Singapore. They revealed that spatial visualization sketchpad and phonological loop did not contribute to mathematical achievement indicating that the overall executive functioning of the combined elements of both spatial visualization do contribute to mathematical achievement in combination and not individually (Lee et al., 2004). In the present study there are five hypotheses proposed.

$\mathrm{H}_{\mathrm{A}}(1)$ : Spatial visualization mediates between mathematics attitude and mathematics achievement among $8^{\text {th }}$ grade students.

$\mathrm{H}_{\mathrm{A}}(2)$ : Spatial visualization mediates between mathematics motivation and mathematics achievement.

$\mathrm{H}_{\mathrm{A}}(3)$ : Spatial visualization mediates between mathematics self-regulation and mathematics achievement.

$\mathrm{H}_{\mathrm{A}}(4)$ : Spatial visualization mediates between mathematics self-efficacy and mathematics achievement.

$\mathrm{H}_{\mathrm{A}}(5)$ : Spatial visualization mediates between math anxiety and mathematics achievement.

\section{Methodology}

\subsection{Sample and Population}

The present study is carried out in middle schools in Jordan, specifically in Al-koura District Governorate, North of Jordan. The research population selected for the present study included 2,257 $8^{\text {th }}$ grade students 1,101 (49\%) males and 1,156 (51\%) females representing the whole schools in the region (37). The sample size of the present study comprised 360 schools students from $8^{\text {th }}$ grade, $178(49 \%)$ male students and $182(51 \%)$ female students. This ensured that the number represents the whole population.

\subsection{Instruments}

Data for the study were collected by three instruments, MLS questionnaire, Mathematics achievement and Spatial Visualization Test, where MLS questionnaire is divided into five sections (1-5). Sixty-five items were used to measure mathematics learning strategy factors namely mathematics attitude (18 items), mathematics motivation (7items), mathematics self-regulation ( 25 items), mathematics self-efficacy (5 items) and math anxiety (10 items). Students were asked to indicate the extent to which they agreed with statements on a 5-point Likert scale [choice 1 (strongly disagree), 2 (disagree), 3 (moderately agree), 4 (agree) and 5 (strongly agree)]. These items collect information on five sections: mathematics attitude, mathematics motivation, mathematics self- regulation, math's self- efficacy and mathematics anxiety.

The Mathematics Achievement questionnaire is a modified and constructed version by the Ministry of Education in Jordan and it includes 30 multiple choice items consisting of numbers ( 8 items), algebra (14 items) and geometry ( 8 items) of one mark each. A correct response to an item was awarded one mark, while an incorrect response was given no mark.

The spatial visualization test by Ben-Chaim, Lappan, and Houang (1988) was employed to measure the students' spatial visualization in the present study. Idris (1998) made use of this test comprising of thirty- two multiple choice items with each having two options. The test is considered as an untimed power test that takes around 20-30 minutes to complete. Generally, the test items comprises of the 2D and 3D views of the building and mat plan including the description of the building base by square and numbers. Each square states the number of cubes within it. The test was initially created for $6^{\text {th }}-8^{\text {th }}$ graders, and its validity has been tested by studies (Idris, 1998; Fraenkel \& Wallen, 2006).

Data collected was analyzed with the help of Statistical Package for Social Sciences (SPSS), version 19.0, in order to examine the obtained information from the respondents.

\section{Findings}

The first hypothesis $\mathrm{H}_{\mathrm{A}}(1)$ states that spatial visualization mediates the relationship between mathematics attitude and mathematics achievement. To examine the hypothesized statement, hierarchical regression was performed.

As portrayed in Table 1, the results indicated that in the first model, mathematics attitude significantly contributed to mathematics achievement, $\mathrm{R}^{2}=0.05, \mathrm{~F}=15.73, \mathrm{p}<.05$. Model one shows that mathematics attitude was positively related to mathematics achievement $\beta=.21, \mathrm{t}=3.96$, at the significant level of $\mathrm{p}=<.05$. In model two, spatial visualization was added to the equation, the $\mathrm{R}^{2}=0.42$ significantly changed with $\mathrm{F}=$ $120.65, \mathrm{p}<.05$. Model two shows that mathematics attitude was reduced $\beta=.09, \mathrm{t}=2.31$, at the significant 
level of $\mathrm{p}>.05$ in testing the mediation effect of spatial visualization: in model 1 , the relationship between mathematics attitude and mathematics achievement was significant while in model 2 the relationship between mathematics attitude and mathematics achievement, although reduced, is still significant and not decreased. Therefore, spatial visualization partially mediated the relationship between mathematics attitude and mathematics achievement.

Table 1. The result of hierarchical regression analysis using spatial visualization as a mediator in the relationship between mathematics attitude and mathematics achievement

\begin{tabular}{|c|c|c|c|c|c|c|}
\hline Model & & Un. B & Std.Error & Std. $\beta$ & $\mathrm{T}$ & $\mathrm{P}$ \\
\hline Step 1 & (constant) & 11.32 & 1.43 & & 7.90 & $.00^{* * *}$ \\
\hline (Model 1) & $\begin{array}{l}\text { Mathematics } \\
\text { Attitude }\end{array}$ & 1.91 & 0.48 & 0.21 & 3.96 & $.00^{* *}$ \\
\hline Step 2 & Constant & 1.74 & 1.29 & & 1.34 & .17 \\
\hline \multirow[t]{2}{*}{ (Model 2) } & $\begin{array}{l}\text { Mathematics } \\
\text { Attitude }\end{array}$ & 0.88 & 0.38 & 0.09 & 2.31 & $.02 *$ \\
\hline & Spatial Visualization & 0.68 & 0.05 & .62 & 14.67 & $.00 * *$ \\
\hline
\end{tabular}

The second hypotheses $\mathrm{H}_{\mathrm{A}}(2)$ stated that spatial visualization mediates the relationship between mathematics motivation and mathematics achievement.

As portrayed in Table 2, the results indicated that in the first model, mathematics motivation significantly contributed to mathematics achievement, $\mathrm{R}^{2}=0.02, \mathrm{~F}=6.20, \mathrm{p}<.05$. Model one shows that motivation was positively related to mathematics achievement $\beta=.14, \mathrm{t}=2.49$, at the significant level of $\mathrm{p}=<.05$. In model two, spatial visualization was added to the equation, the $\mathrm{R}^{2}=0.42$ significantly changed with $\mathrm{F}=119.04, \mathrm{p}<.05$ Model two shows that mathematics motivation was reduced $\beta=.08, \mathrm{t}=1.86$, at the significant level of $\mathrm{p}<.05$ in testing the mediation effect of spatial visualization: in model 1 the relationship between mathematics motivation and mathematics achievement was significant while in model 2 the relationship between motivation and mathematics achievement reduced and not significant. Therefore, spatial visualization fully mediated the relationship between motivation and mathematics achievement.

Table 2. The result of hierarchical regression analysis using spatial visualization as a mediator in the relationship between mathematics motivation and mathematics achievement

\begin{tabular}{llccccc}
\hline Model & & Un-St. $\beta$ & Std.Error & Std. $\beta$ & $\mathrm{t}$ & $\mathrm{P}$ \\
\hline Step 1 & (constant) & 14.17 & 1.13 & & 12.49 & $.00^{* *}$ \\
(Model 1) & $\begin{array}{l}\text { Mathematics } \\
\text { Motivation }\end{array}$ & 0.99 & 0.40 & 0.14 & 2.49 & $.01^{* *}$ \\
\hline Step 2 & Constant & 2.52 & 1.12 & & 2.15 & $.03^{*}$ \\
$($ Model 2) & $\begin{array}{l}\text { Mathematics } \\
\text { Motivation }\end{array}$ & 0.57 & 0.31 & 0.08 & 1.86 & .06 \\
& Spatial Visualization & 0.70 & 0.05 & .63 & 15.08 & $.00^{* *}$ \\
\hline $\mathrm{R}^{2}=.02$ in step 1, $\mathrm{R}^{2}=.42$ in step 2 & & & & & \\
\hline $.05, * * \mathrm{p}<.01$.
\end{tabular}

The third hypotheses $\mathrm{H}_{\mathrm{A}}(3)$ stated that spatial visualization mediates the relationship between mathematics self-regulation and mathematics achievement.

The results in Table 3 demonstrate the correlations of self- regulation and mathematics achievement and they 
showed no relationship between the two. Therefore, it can be concluded that the hypothesis did not achieve the first condition of the mediation variable analysis, which is the independent variable has to influence the dependent variable in order to test the mediation hypothesis. Therefore, hypothesis number three, which states that spatial visualization mediates the relationship between self-regulation and mathematics achievement, was rejected.

Table 3. The result of hierarchical regression analysis using spatial visualization as a mediator in the relationship between mathematics self- regulation and mathematics achievement

\begin{tabular}{|c|c|c|c|c|c|c|c|}
\hline Model & & & Un-St. $\beta$ & Std.Error & St. $\beta$ & $\mathrm{t}$ & $P$ \\
\hline Step 1 & (constant) & & 15.96 & 1.30 & & 12.25 & $.00 * *$ \\
\hline (Model 1) & $\begin{array}{l}\text { Mathematics } \\
\text { regulation }\end{array}$ & Self- & 0.32 & 0.43 & 0.04 & .74 & .45 \\
\hline Step 2 & Constant & & 4.99 & 1.22 & & 4.07 & $.00 * *$ \\
\hline \multirow[t]{2}{*}{ (Model 2) } & $\begin{array}{l}\text { Mathematics } \\
\text { regulation }\end{array}$ & Self- & -0.40 & 0.33 & -0.05 & -1.20 & .22 \\
\hline & Spatial Visual & zation & 0.71 & 0.46 & .65 & 15.25 & $.00 * *$ \\
\hline
\end{tabular}

The fourth hypothesis states that spatial visualization mediates the relationship between self- efficacy and mathematics achievement.

The results in Table 4 demonstrate the correlations between self- efficacy and mathematics achievement and show no relationship between the two variables. Therefore, it can be concluded that the hypothesis did not achieve the first condition of the mediation variable analysis which is, the independent variable has to influence the dependent variable in order to test the mediation hypothesis. Therefore, hypothesis number four, which states that spatial visualization mediates the relationship between self-efficacy and mathematics achievement, was rejected.

Table 4.The result of hierarchical regression analysis using spatial visualization as a mediator in the relationship between mathematics self- efficacy and mathematics achievement

\begin{tabular}{|c|c|c|c|c|c|c|c|}
\hline Model & & & Un-St. $\beta$ & Std.Error & St. $\beta$ & $\mathrm{t}$ & $\mathrm{P}$ \\
\hline Step 1 & (constant) & & 15.51 & 0.84 & & 18.39 & $.00 * *$ \\
\hline (Model 1) & $\begin{array}{l}\text { Mathematics } \\
\text { efficacy }\end{array}$ & Self- & 0.52 & 0.30 & 0.09 & 1.74 & .08 \\
\hline Step 2 & Constant & & 2.58 & 1.06 & & 4.07 & $.00^{* *}$ \\
\hline \multirow[t]{2}{*}{ (Model 2) } & $\begin{array}{l}\text { Mathematics } \\
\text { efficacy }\end{array}$ & Self- & 0.51 & 0.22 & 0.09 & -1.20 & 0.02 \\
\hline & Spatial Visua & zation & 0.70 & 0.04 & .64 & 15.25 & $.00 * *$ \\
\hline
\end{tabular}

Lastly, fifth hypothesis states that spatial visualization mediates the relationship between math anxiety and mathematics achievement.

As portrayed in Table 5, the results indicated that in the first model, math anxiety significantly contributed to mathematics achievement, $\mathrm{R}^{2}=0.04, \mathrm{~F}=14.59, \mathrm{p}<.05$. Model one shows that math anxiety was positively related to mathematics achievement $\beta=.21, \mathrm{t}=3.82$, at the significant level of $\mathrm{p}<.05$. In model two, spatial visualization was added to the equation, the $\mathrm{R}^{2}=0.41$ significantly changed with $\mathrm{F}=116.84, \mathrm{p}<.05$. Model two 
shows that math anxiety was reduced $\beta=.04, \mathrm{t}=.94$, at the significant level of $\mathrm{p}>.05$ in testing the mediation effect of spatial visualization: in model 1 the relationship between math anxiety and mathematics achievement was significant while in model 2 the relationship between math anxiety and mathematics achievement was reduced and not significant-therefore, Spatial visualization fully mediated the relationship between math anxiety and mathematics achievement.

Table 5. The result of hierarchical regression analysis using spatial visualization as a mediator in the relationship between math anxiety and mathematics achievement

\begin{tabular}{llccccc}
\hline Model & & Un-St $\beta$ & Std.Error & St. $\beta$ & $\mathrm{t}$ & $\mathrm{P}$ \\
\hline Step 1 & (constant) & 12.54 & 1.17 & & 10.66 & $.00^{* *}$ \\
(Model 1) & Math anxiety & 1.47 & 0.38 & 0.21 & 3.82 & $.00^{* *}$ \\
\hline Step 2 & Constant & 3.29 & 1.12 & & 2.94 & $.00^{* *}$ \\
(Model 2) & Math anxiety & 0.29 & 0.31 & 0.04 & 0.94 & .34 \\
& Spatial & & & & & \\
& visualization & 0.69 & 0.05 & .63 & 14.48 & $.00^{* *}$ \\
\hline $\mathrm{R}^{2}=.04$ in step 1, $\mathrm{R}^{2}=.41$ in step 2 & & & & & \\
\hline $.05, * * \mathrm{p}<.01$.
\end{tabular}

\section{Discussion}

The possible explanation for the mediating effect of spatial visualization on the relationship between attitude and mathematics achievement is having a high spatial visualization ability encourages students to learn mathematics and this leaves a positive attitude among students to learn mathematics in order to obtain high scores in mathematics. In addition, the relationship between spatial visualization a mathematical ability is based upon the fact that operations performed while interacting with mental models in mathematics are often the same as those used to operate in spatial environment (Battisa, 1994). A visual representation not only organizes the data at hand in a meaningful structure, but is also an important factor guiding the analytic development of a solution (Fischbein, 1987). It is possible that the increasing positive attitude together with the increasing importance of spatial visualization have strengthened the positive association between mathematics attitude and spatial visualization with mathematics achievement. This association might have encouraged student attitudes as spatial visualization is important to success in mathematics while mathematics is important in academic success. In terms of spatial visualization findings, the result indicated that spatial visualization has an important role in enhancing the students' attitude towards mathematics and heightening their achievement in mathematics subject. More importantly, the relationship between mathematics attitude and mathematics achievement through spatial visualization was fully supported.

A mediating effect of spatial visualization was also found between motivation and mathematics achievement. It was possible that having high spatial visualization ability encourages students and motivates them to enhance academic achievement. This statement was supported indirectly by Wheatley (1992) where spatial abilities were accepted as crucial for high mathematical abilities. In addition, Lowrie and Kay (2001) asserted that students prefer to select visual methods to complete difficult mathematics problems. This finding could be interpreted as views of the important role of spatial visualization that motivate students and lead them to higher mathematics achievement. Hence, it can be concluded that creating students awareness on the importance of spatial visualization to their future undertakings would be one way of motivating students in their mathematics learning. In terms of spatial visualization findings, the result indicated that spatial visualization has an important role in enhancing the students' motivation towards mathematics and heighten their achievement in mathematics subject. However, the relationship between the mathematics motivation and mathematics achievement through spatial visualization was only partially supported.

Furthermore, the result indicated that spatial visualization does not play an important role in enhancing student's ability to apply self-regulation strategies while doing mathematics tasks. In other words, the relationship between the self-regulation and mathematics achievement through spatial visualization was not supported. Learning spatial visualization topics normally require various learning techniques and do not rely on cognitive processing spatial information. Hence, the insignificant results of the mediating spatial visualization on the relationship 
between self-regulation and mathematics achievement maybe due to the fact that the participants may rely on other abilities but not spatial visualization for learning mathematics, and therefore, their decisions to use other abilities are based on personal preferences rather than intellectual ability. Furthermore, various interpretations of the definition of self-regulation have led to a multiplicity of instruments to measure the construct. Therefore, self-regulation measure used for this study may have led to the insignificant result for the mediating role of spatial visualization on the relationship between self-regulation and mathematics achievement.

In addition, the results showed no mediating effect between self-efficacy and math achievement. Students who believe that mathematics will be useful to them in the future develop a desire to learn mathematics and vice versa. Feelings are the emotional reactions that are felt by the students when they deal and face with spatial ability problem. Poor performance on spatial visualization level may directly affect perceptions of self-efficacy, especially in girls. Students who have the opportunity to improve their spatial-visualization skills demonstrated greater self-efficacy and are more likely to persist in their study. Girls were more apt to display under-confidence relative to their actual spatial visualization tasks and to attribute spatial visualization failure than were boys. Therefore, girls in this study showed less mean scores on spatial visualization and this may have led to the insignificant result.

Lastly, the results showed a mediating effect between math anxiety and math achievement. Since anxiety can create worries that are verbal in nature (Beilock et al., 2010), and some students use verbal strategies while others use spatial ability, and since male students perform better than girls on spatial visualization, the researcher assumed that the effect of mediating variable may be due to the fact that majority of the study sample are males so this may affect the result of mediating variable. In other words, students who rely heavily on verbal strategies to solve mental rotation problems should show the strongest relation between spatial visualization and anxiety and mathematics. To this end, female students have been reported to engage in more verbal strategies such as thinking of words for features and matching shapes based on those features, whereas males have been reported to engage in more spatial strategies such as mentally rotating one shape and comparing the resulting visual representation with another shape. In sum, the relationship between the mathematics anxiety and mathematics achievement through spatial visualization was fully supported.

\subsection{Implications}

In particular, one of the more interesting findings of this study is the demonstration of the presence of a novel empirical evidence of mediating effects that expounds the relationship between Mathematics Learning Strategy factors with mathematics achievement. According to Summers' (2001) classification, the empirical contributions comprises of 'testing a theoretical linkage between two constructs that has not been previously tested, examining the effect of a potential moderator or mediator variable on the nature of the relationship between to constructs, and testing a theoretical linkage between two constructs'. Furthermore, the study identifies the influence of spatial visualization as a mediator variable between the relationship of Mathematics Learning Strategy factors and mathematics achievement. In other words, empirically, spatial visualization is revealed in this study to partially mediate the linkage between Mathematics Learning Strategy and mathematics achievement. The reason behind this lies in the strength of the relationship between independent and dependent variables in students who demonstrate high spatial visualization.

\subsection{Conclusion}

The tested hypotheses set out to examine the mediating effect of spatial visualization on the relationship between Mathematics Learning Strategy factors and mathematics achievement. Results revealed that spatial visualization played a mediating role between mathematics attitude, mathematics motivation, math anxiety and mathematics achievement. On other hand, spatial visualization did not mediate the relationship between self-efficacy, self-regulation and mathematics achievement. Hence, the result of the hypotheses was partially supported. This study also suggests that the spatial visualization mediating effect between mathematics attitude, mathematics motivation and math anxiety and math achievement may be due to teaching styles employed by teachers at schools The research findings could be justified and since literature has not provided any interpretation for the mediating role of spatial visualization with other variables, the findings of the present study contribute to literature by highlighting partial support for its mediating role in the relationship between Mathematics Learning Strategy factors and mathematics achievement.

\section{References}

Abo-lebdeh, K. (2008). Jordanian national report on the study of the international mathematics and Science $\begin{array}{lccc}\text { TIMSS } & \text { (2007). } & \text { Retrieved } & \text { September } \\ \text { http://www.moe.gov.jo/Files/(14-3-2011)(2-11-40\%20PM).pdf }\end{array}$

25 ,

2012 ,

From 
Abu-Mustafa, S. (2010). The relationship between spatial ability and achievement in Mathematics for sixth grade students in UNRWA schools (Unpublished master theses). Islamic University, Gaza.

Ajayi, K. O., Lawani, A. O., \& Adeyanju, H. I. (2013). Effects of Students' Attitude and Self-Concept on Achievement in Senior Secondary School Mathematics in Ogun State, Nigeria. Journal of Research in National Development, 9(2), 202-211.

Al-Jaraideh, Y. (2009). Affecting information and communication technology (ICT) integration in Jordanian secondary schools (Unpublished doctoral dissertation). University Utara Malaysia, Malaysia, Kedah.

Areepattamannil, S. (2014). Relationship between Academic Motivation and Mathematics Achievement Among Indian Adolescents in Canada and India. The Journal of General Psychology, 141(3), 247-262. http://dx.doi.org /10.1080/00221309.2014.897929

Augustyniak, K, Murphy, J., \& Phillips, K. D. (2004). Psychological Perspectives in Assessing Mathematics Learning Needs. Journal of Instructional Psychology, 32(4), 277-286.

Bandura, A. (1986). Social foundations of thought and action: A social cognitive theory. Englewood Cliffs, New York: Prentiss Hall.

Bandura, A. (1997). Self-efficacy: Toward a Unifying Theory of Behavioral Change. Psychological Review, 84(2), 191-215. http://dx.doi.org/10.1037/0033-295X.84.2.191

Battista, M. T. (1994). On Greeno's Environmental/model View of Conceptual Domains: A Spatial/Geometric Perspective. Journal for Research in Mathematics Education, 25(1), 86-94.

Beilock, S. L., Gunderson, E. A., Ramirez, G., \& Levine, S. C. (2010). Female Teachers' Math Anxiety Affects Girls' Math Achievement. Proceedings of the National Academy of Sciences, 107(5), 1860-1863. http://dx.doi.org/10.1073/pnas.0910967107

Ben-Chaim, D., Lappan, G., \& Houng, R. (1988). The Effect of Instruction on Spatial Visualization Skills of Middle School Boys and Girls. American Educational Research Journal, 25(1), 51-71. http://dx.doi.org/10.3102/00028312025001051

Capraro, R., Young, J., Lewis, C., Yetkiner, Z., \& Woods, M. (2009). An Examination of Mathematics Achievement and Growth in a Midwestern Urban School District: Implications for Teachers and Administrators. Journal of Urban Mathematics Education, 2(2), 46-65.

Cassidy, J. (2002). Literacy 2001: What is and what should be. In W. M. Linek, E. G. Sturtevant, J. R. Dugan, \& P. E. Linder (Eds.), Celebrating the voices of literacy: 23rd yearbook of the College Reading Association (pp. 2-6). Commerce: Texas A\&M-Commerce; College Reading Association.

Chouinard, R., Karsenti, T., \& Roy, N. (2007). Relations among Competence Beliefs, Utility Value, Achievement Goals, and Effort in Mathematics. British Journal of Educational Psychology, 77(3), 501-517. http://dx.doi.org/10.1348/000709906X133589

De Bruin, A. B., Thiede, K. W., \& Camp, G. (2001). Generating Keywords Improves Metacomprehension and Self-regulation in Elementary and Middle School Children. Journal of Experimental Child Psychology, 109(3), 294-310. http://dx.doi.org/10.1016/j.jecp.2011.02.005

Drew, D. E. (1996). Aptitude revisited. Baltimore, MD: Johns Hopkins University Press.

Eleftherios, K., \& Theodosios, Z. (2007). Students' Beliefs and Attitudes Concerning Mathematics and Their Effect on Mathematical Ability. CERME, 5, 258-267.

Fischbein, E. (1987). Intuition in science and mathematics: An educational approach. Dordrecht, Holland: Reidel

Fraenkel, J., \& Wallen, N. (2006). How to design and evaluate research in education. New York: McGraw Hill Companies, Inc.

Ghbari, T., Abu-Shendi, Y., \& Abu-Sheirah, K. (2008). Spatial Ability among Students in the College of Information Technology at Zarqa Private University in Relationship to Certain Variables. UOS journal for humanities and social science, 7(2), 251-273.

Gourgey, A. F. (1984). The relationship of misconceptions about math and mathematical self-concept to math anxiety and statistics performance. Paper presented at the Annual Meeting of the American Educational Research Association, New Orleans, LA.

Hammoury, H. (2004). Attitudinal and Motivational Variables Related to Mathematics Achievement in Jordan: 
Findings from the Third International Mathematics and Science Study (TIMSS). Educational Research, 46(3), 241-257. http://dx.doi.org/10.1080/0013188042000277313

Harris, K. R., Friedlander, B. D., Saddler, B., Frizzelle, R., \& Graham, S. (2005). Self-monitoring of Attention Versus Self-monitoring of Academic Performance: Effects among Students with ADHD in the General Education Classroom. Journal of Special Education, 39(3), 145-156. http://dx.doi.org/10.1177/00224669050390030201

Hembree, A. (1990). Correlates Causes Effects and Treatment of Test Anxiety. Review of educational research, 58(1), 47-77. http://dx.doi.org/10.3102/00346543058001047

Idris, N. (1998). Spatial visualization, field dependence/independence, van hiele level, and achievement in geometry: The influence of selected activities for middle school students (Order No. 9900847, The Ohio State University). ProQuest Dissertations and Theses.

Ifamuyiwa, A., \& Ajilogba, S. (2012). A Problem Solving Model as a Strategy for Improving Secondary School Students' Achievement and Retention in Further Mathematics. ARPN Journal of Science and Technology, 2(2), 122-130.

Ikegulu, T. N. (2000). The differential effects of gender and mathematics anxiety apprehension on developmental students' academic performance and persistence. ERIC Document Reproduction Service No. ED451824.

Jarvela, S., \& Jarvenoja, H. (2011). Socially Constructed Self-regulated Learning and Motivation Regulation in Collaborative Learning Groups. Teachers College Record, 113(2), 350-374.

Joo, Y. J., Bong, M., \& Choi, H. J. (2000). Self-efficacy for Self-regulated Learning, Academic Self-efficacy, and Internet Self-efficacy in Web-based Instruction. Educational Technology Research and Development, 48(2), 5-17.

Landry, C. C. (2003). Self-efficacy, motivation, and outcome expectation correlates of college students' intention certainty (Order No. 3085684, Louisiana State University and Agricultural \& Mechanical College). ProQuest Dissertations and Theses.

Lee, K., Ng, S. F., Ng, E. L., \& Lim, Z. Y. (2004). Working Memory and Literacy as Predictors of Performance on Algebraic Word Problems. Journal of Experimental Child Psychology, 89(2), 140-158. http://dx.doi.org/10.1016/j.jecp.2004.07.001

Lowrie, T., \& Kay, R. (2001). Relationship between Visual and Nonvisual Solution Methods and Difficulty in Elementary Mathematics. The Journal of Educational Research, 94(4), 248-255. http://dx.doi.org/10.1080/00220670109598758

Ma, X. (1999). A Meta-analysis of the Relationship between Anxiety toward Mathematics and Achievement in Mathematics. Journal for Research in Mathematics Education, 30(5), 520-540.

Ma, X., \& Kishor, N. (1997). Assessing the Relationship between Attitude toward Mathematics and Achievement in Mathematics: A Meta-Analysis. Journal for Research in Mathematics Education, 28 (1), 26-47.

Ma, X., \& Xu, J. (2004). The Causal Ordering of Mathematics Achievement: A Longitudinal Panel Analysis. Journal of Adolescence, 27(2), 165-179. http://dx.doi.org/10.1016/j.adolescence.2003.11.003

Meyer, M. L., Salimpoor, V. N., Wu, S. S., Geary, D. C., \& Menon, V. (2010). Differential Contribution of Specific Working Memory Components to Mathematics Achievement in 2nd and 3rd Graders. Learning and Individual Differences, 20(2), 101-109. http://dx.doi.org/10.1016/j.lindif.2009.08.004

Mullis, I. V., Martin, M. O., Foy, P., \& Arora, A. (2012). TIMSS 2011 international results in mathematics.

Pandiscio, E. A. (1994). Spatial visualization and mathematics achievement: A correlational study between mental rotation of objects and geometric problems (Order No. 9506073, The University of Texas at Austin). ProQuest Dissertations and Theses.

Popham, W. (2005). Students' attitudes count. Educational Leadership, 62(5), 84-85.

Rayan, A. (2008). Spatial Ability among Al-Quds Open University Students Studying Elementary School Education Major. Palestine Journal of open education, 2(1), 115-144.

Rohde, T. E., \& Thompson, L. A. (2007). Predicting Academic Achievement with Cognitive Ability. Intelligence, 35(1), 83-92. http://dx.doi.org/10.1016/j.intell.2006.05.004

Rovira, E., \& Sancho, T. (2012). The Relationship between Cognition and Affect on Online Mathematics and Their Interaction Over Time. eLearn Center Research Paper Series, 4(1), 43-55. 
Royster, D., Harris, M., \& Schoeps, N. (1999). Dispositions of College Mathematics Students. International Journal of Mathematical Education in Science and Technology, 30(3), 317-333. http://dx.doi.org/10.1080/002073999287851

Sabah, S., \& Hammouri, H. (2010). Does Subject Matter Matter. Estimating the Impact of Instructional Practices and Resources on Student Achievement in Science and Mathematics: Findings from TIMSS 2007. Evaluation \& Research in Education, 23(4), 287-299. http://dx.doi.org/10.1080/09500790.2010.509782

Saffer, N. (1999). Core subjects and your career. Occupational Outlook Quarterly, 26-40. Retrieved June 25, 2013, from http://www.bls.gov/opub/ooq

Sartawi, A., Alsawaie, O., Dodeen, H., Tibi, S., \& Alghazo, I. (2012). Predicting Mathematics Achievement by Motivation and Self-efficacy Across Gender and Achievement Levels. Interdisciplinary Journal of Teaching and Learning, 2(2), 59-77.

Seabra, R., \& Santos, E. (2008). Evaluation of the Spatial Visualization Ability of Entering Students in a Brazilian Engineering Course. Journal for Geometry and Graphics, 12(1), 99-108.

Sipus, Z., \& Cizmesija, A. (2012). Spatial Ability of Students of Mathematics Education in Croatia Evaluated by the Mental Cutting Test. Annales Mathematica et Informaticae, 40, 203-216.

Summers, J. O. (2001). Guidelines for Conducting Research and Publishing in Marketing: From Conceptualization Through the Review Process. Journal of the Academy of Marketing Science, 29(4), 405-415. http://dx.doi.org/10.1177/03079450094243

Tella, A. (2007). The Impact of Motivation on Student's Academic Achievement and Learning Outcomes in Mathematics among Secondary School Students in Nigeria. Eurasia Journal of Mathematics, Science \& Technology Education, 3(2), 149-156.

Wechsler, D. (1999). Wechsler abbreviated scale of intelligence. Psychological Corporation.

Wheatley, M. J. (1992). Leadership and the new science: Learning about organizations from an orderly universe. San Francisco: Berrett-Koehler Publishers.

Wolters, C. A. (2011). Regulation of Motivation: Contextual and Social Aspects. Teachers College Record, $113(2), 265-283$.

Zimmerman, B. J. (2000). Self-Efficacy: An Essential Motive to Learn. Contemporary Educational Psychology, 25(1), 82-91. http://dx.doi.org/10.1006/ceps.1999.1016

Zimmerman, B. J. (2008). Investigating Self-regulation and Motivation: Historical Background, Methodological Developments, and Future Prospects. American Educational Research Journal, 45(1), 166-183. http://dx.doi.org/10.3102/0002831207312909

Zimmerman, B. J., \& Martinez-Pons, M. (1990). Development of a Structured Interview for Assessing Students' Use of Self-regulated Learning Strategies. American Educational Research Journal, 23(4), 614-628. http://dx.doi.org/10.3102/00028312023004614

\section{Copyrights}

Copyright for this article is retained by the author(s), with first publication rights granted to the journal.

This is an open-access article distributed under the terms and conditions of the Creative Commons Attribution license (http://creativecommons.org/licenses/by/3.0/). 